Article

\title{
The Impact of "Strike Hard" on Repeat and Near-Repeat Residential Burglary in Beijing
}

\author{
Peng Chen ${ }^{1}$ and Justin Kurland ${ }^{2, *}$ \\ 1 School of Police Information Engineering and Cyber Security, People's Public Security University of China, \\ Beijing 100038, China; chenpeng@ppsuc.edu.cn \\ 2 School of Criminal Justice, Forensic Sciences, and Security, National Center for Spectator Sports Safety and \\ Security, University of Southern Mississippi, 118 College Drive \#5193, Hattiesburg, MS 39406, USA \\ * Correspondence: Justin.Kurland@usm.edu; Tel.: +1-601-266-5022
}

Received: 13 January 2020; Accepted: 4 March 2020; Published: 6 March 2020

check for updates

\begin{abstract}
Strike Hard" is an enhanced law-enforcement strategy in China that aims to suppress crime, but measurement of the crime-reducing effect and potential changes in the spatiotemporal concentration of crime associated with "Strike Hard" remain unknown. This paper seeks to examine the impact, if any, of "Strike Hard" on the spatiotemporal clustering of burglary incidents. Two and half years of residential burglary incidents from Chaoyang, Beijing are used to examine repeat and near-repeat burglary incidents before, during, and after the "Strike Hard" intervention and a new technique that enables the comparison of repeat and near repeat patterns across different temporal periods is introduced to achieve this. The results demonstrate the intervention disrupted the repeat pattern during the "Strike Hard" period reducing the observed ratio of single-day repeat burglaries by $155 \%$; however, these same single-day repeat burglary events increased by $41 \%$ after the cessation of the intervention. Findings with respect to near repeats are less remarkable with nominal evidence to support that the intervention produced a significant decrease, but coupled with other results, suggest that spatiotemporal displacement may have been an undesired by-product of "Strike Hard". This study from a non-Western setting provides further evidence of the generalizability of findings related to repeat and near repeat patterns of burglary and further highlights the limited preventative effect that the "Strike Hard" enhanced law enforcement campaign had on burglary.
\end{abstract}

Keywords: residential burglary; near repeat analysis; crime pattern; crime displacement; Beijing

\section{Introduction}

Repeat and near repeat victimization are best described as a spatiotemporal crime phenomenon in which the risk of an offence concentrates not only in space, but also in time in relation to previous initiator incidents [1-7]. Over the previous decade, many repeat and near-repeat studies have been conducted for the purpose of (1) understanding the spatiotemporal nature of crime patterns, (2) to help supervise or optimize police response strategies, or (3) to forecast where future offences were most likely to occur in an effort to prevent future harm. The overwhelming majority of this research has been conducted in Western settings. In addition, a large proportion of the studies in this area have not taken advantage of policing-specific interventions to determine what, if any, effect increased police presence may have on repeat or near repeat patterns. Both of these represent gaps in the existing literature. To place the latter into context we consider the routine activity approach. The theory suggests that crime is a function of motivated offenders meeting potential targets in the absence of a capable guardian in space and time [8]. While some uncertainty remains regarding a formal definition of who is (or is not) a capable guardian [9], it is axiomatic that police officers represent a type of formal guardian. Thus, opportunities to take advantage of known increases in capable guardianship in the context of repeat 
and near repeat analysis can provide important theoretical and practical insight about the potentially preventative nature of increased police presence, however time-limited it may be, on hotspots of crime.

Some recent efforts have sought to tease apart how approaches such as hotspot policing may impact crime patterns, however, limited research has been conducted and reported on this in non-Western settings. Further, there are important distinctions between some of the more proactive policing approaches common in various Western societies and strategies such as "Strike Hard" (Yanda) employed in the Chinese context. "Strike Hard", is at its heart both an enhanced policing approach to focus on specific categories of crime and a deterrence strategy predicated on the celerity and severity of punishment as a method of crime prevention and social control [10]. The celerity component revolves around the process of expediting criminal justice procedures to more rapidly process offenders. This typically occurs within about two weeks of an arrest during "Strike Hard". While the severity component refers to the sanctioning, which during "Strike Hard" campaigns typically results in greater punitive outcomes in the form of lengthier prison sentences for the same crime [11] (p. 99). It has been suggested and there is some evidence that suggests that "Strike Hard" campaigns have resulted in reduced levels of crime and disorder for those particular categories of crimes that have been targeted; however, what remains unclear is whether these interventions result in sustained crime reductions or if patterns simply returned to previous levels after the interventions end.

The aim of this paper was to first better understand if burglary patterns in a non-Western setting are reflective of the spatiotemporal clustering of burglary events that have been found repeatedly in Western contexts. An additional aim is to examine the utility, or lack thereof, of "Strike Hard" as a crime prevention policy through the analysis of repeat and near repeat patterns of residential burglary in a non-Western setting before, during, and after an intervention.

\section{Theoretical Background: Repeat and Near-Repeat Patterns}

Repeat and near repeat victimization is a phenomenon related to the spatial and temporal clustering of crime events to the same or proximal targets [12]. Numerous repeat and near repeat studies have been conducted exploring various crime types including: burglary [3,13-16], shootings [1,5,17], armed robbery [18], arson [12], auto theft [6], maritime attacks [19], and even insurgent activity [20]. A common feature of some of the abovementioned studies has been to test and confirm the temporal and spatial bandwidth of elevated risk of crime and make comparisons across contrasting geographies. For example, other studies have utilized epidemiological techniques typically used for testing disease contagion to demonstrate the communicable risk of burglaries in the UK, New Zealand, Australia, Netherlands and the US [3]. The results of this study suggested that an elevated temporal risk of two to eight weeks and within a 200 to $1200 \mathrm{~m}$ area of initiator burglary events [3]. A similar analysis on burglary across Beijing, China was conducted; however, the repeat and near-repeat pattern was more spatially constrained with only those locations within $200 \mathrm{~m}$ for a period of three weeks having a heightened risk [21]. Alternatively, in a study of repeat and near-repeat domestic burglary in Belo Horizonte, Brazil where a large proportion of the population resides in tower block dwellings the extent of repeat and near-repeat patterns were considerably lower than those in comparable Western urban contexts [22].

Shifting to shootings there have been a number of U.S.-based studies to examine repeat and near-repeat patterns, with a limited number of studies conducted in other contexts. The earliest repeat study on shootings explored nearly 4000 shootings in Philadelphia, Pennsylvania that occurred between August 2003 and September 2005. The results suggest that there was a significant increase across a two-week period within approximately 400 feet of a previous initiator shooting [5]. In a similar analysis across Houston, Texas just under 6000 shootings that took place between January 2007 and August 2008 were analyzed [1] and found comparable results to the study in Philadelphia [2]. A slightly more refined near-repeat analysis of the city of Jacksonville, Florida was conducted across various temporal thresholds that ranged from 1 to 14 days along with a spatial bandwidth of 575 feet to examine the associated spatiotemporal pattern with results suggesting that there was a significant pattern of 
near-repeats with the greatest risk occurring in the first day following an initiator shooting [23]. In an effort to explore the similarity (or lack thereof) of shootings in an alternative context 948 shootings that took place in Stockholm, Gothenburg, and Malmö, Sweden between 2011 and 2015 were examined [17]. While the sample was smaller, and it was for three distinct cities and the near repeat pattern suggested heightened risk across a temporal bandwidth of two weeks and $100 \mathrm{~m}$, which, again, is reflective of near-repeat findings in the various U.S. cities that were examined.

As previously mentioned, the existence of similar near repeat patterns was found for various other crimes. A study using police data from Philadelphia, Pennsylvania found that near repeat street robbery chains were relatively short and rarely lasted longer than seven days between initiation and termination [18]. The spatial and temporal characteristics of arson incidents in Los Angeles, California were examined with results, suggesting an enhanced likelihood of arson events in close spatial and temporal proximity to initial arson incidents [12]. A similar approach to near repeat analysis was also conducted on patterns of improvised explosive attacks (IEDs) in Iraq during U.S. military occupations [20]. The findings suggested that attacks clustered in space and time more than expected if the events were unrelated, and thus, is indicative of a spatiotemporal relationship to risk that could be communicated in an effort to prevent or suppress future attacks.

After establishing the relative ubiquity of near repeat patterns, particularly amongst those related to property crime, some studies have begun to focus on understanding why this occurs. Most notably, two hypotheses-the flag and boost hypotheses-have emerged [15,16,24,25]. The flag hypothesis suggests that the target or victim is already at a heightened risk of being offended against because of a particular vulnerability that invariably attracts offenders. Conversely, the boost hypothesis contends that offenders return to the same target or victim, or those nearby, because they are now aware of vulnerabilities that can be taken advantage of again. To test the validity of each of the hypotheses various studies on repeat and near repeat burglary have been conducted with stronger evidence in support of the boost hypothesis given the significant greater degree of similarity between near repeat burglaries than other burglaries [14,16,26-28]. While it is clear that there is considerable empirical evidence to support the boost hypothesis, it is equally true that the majority of the boost and flag research has been focused on immobile targets such as home in the case of residential burglary. On the contrary, little is known about certain crime types such as armed robbery or shootings, where targets or victims move around in space and time [1].

Despite the lack of empirical consensus across various offence categories, the utility of the boost hypothesis for forecasting burglary events has been firmly established. Indeed, early studies in this area began to explore the possibility of using the elevated risk of burglary in space and time as a clue for predictive crime mapping and then tested the utility of the approach against more traditional methods that rely solely on previous incidents [29]. However, support for the predictive capability of near repeat pattern analysis is not unanimous. Some researchers have suggested that near-repeat analysis-at least with respect to armed robbery-may not be the optimal way to allocate police resources and instead believe that more holistic approaches that focus on long-term hotspots remain a better strategy for prevention [18].

Along a similar vein, a relatively small proportion of the research on near repeats has highlighted policing interventions that occurred during the study period of interest, or evaluated these initiatives more specifically. One notable exception explored the near-repeat shooting pattern in Philadelphia, examining shootings before and during the "Priority Corners" program, an intervention that was never fully adopted in part because of a poor track record of police cooperation with the community [5]. While the program was itself not properly rolled out, and consequently not directly evaluated in the study, empirical evidence regarding the associated near-repeat pattern suggests it did not have the intended effect of reducing shootings in any significant way. In a similar study, although one that more specifically tested if proactive police patrols deployed in high-crime areas were effective in disrupting repeat and near-repeat shooting patterns in Houston, Texas, findings suggested that the intervention did not disrupt the concentration of shootings in a meaningful way [2]. The primary reason suggested 
for these near repeat shooting outcomes has been attributed to the loosely organized nature of the policing interventions. Previous near-repeat focused interventions that have targeted burglary and car theft have demonstrated how well designed strategies for preventing repeat and near repeat victimizations can reduce specific crime problems [30,31]. In contrast to the loosely organized proactive policing patrols, and the more specific interventions meant to reduce opportunities for repeat and near repeat victimization, "Strike Hard", launched by Chinese government is a multi-layered approach towards crime prevention that takes advantage of both specifically designed policing tasks, but also enhanced sanctions for those offenders who are caught in an effort to suppress crime. Analyzing repeat and near repeat residential burglary incidents before, during, and after "Strike Hard", therefore, is the aim of this study.

\section{3. "Strike-Hard": A Criminal Justice Campaign for Reducing Crime}

Various Western law enforcement agencies have adopted hotspot policing strategies; however, "Strike Hard" is-at least in theory-a more comprehensive approach to crime prevention as it involves three criminal justice agencies rather than just the police, including: (1) the public security bureau (PSB), (2) the prosecutor, and (3) the courts, who jointly seek to prevent crime in China. As previously noted, the approach includes a punitive mechanism applied to specific crimes that are deemed to be a threat to order in China and was an outgrowth of the post-Mao reform period that began in 1978 coinciding with China's efforts to modernize and make further economic progress [10]. The original intent of "Strike Hard" was to tackle China's growing crime problems that transpired during this period of economic growth that police were not able to effectively prevent in part because of a belief that the overall number of officers was insufficient to reduce the increased rate. More specifically, according to public records even as of 2015, China only has a total of 1.8 million police officers thus representing only $0.13 \%$ of the country's total population, in contrast to neighboring nations like Korea $(0.36 \%)$ and Japan $(0.22 \%)$. Consequently, this lack of capable guardianship was believed to be behind the growing rate of crimes such as murder, kidnapping, drug trafficking, armed robbery, habitual thievery, and various other offences increased during this period and so, in an attempt to stifle all categories of crime, the first ever "Strike Hard" campaign was launched nationwide in 1983.

While hailed a success by the government one lesson that was gleaned from the original 1983 "Strike Hard" campaign suggested that a targeted approach that focused on more specific, serious categories of crime would be adopted for future "Strike Hard" campaigns. Consequently, in the numerous other nationwide, "Strike Hard" campaigns that have occurred since including 1996, 2000-2001, 2004, and 2010, greater attention has been given to offences that involved violence, organized crime and drug trafficking, among others while simultaneously attempting to ensure "minor" crimes remained at a lower level. During the most recent "Strike Hard" that occurred between 13 June and 31 December 2010 the nationwide effort again targeted more extreme offence categories that involved violence, guns, organized crime, telecom fraud, human trafficking, and various other crime types. However, in Beijing, unlike the rest of China, a smaller number of more specific crime categories that included prostitution, extreme violence and residential burglary were targeted.

With respect to residential burglary a multi-faceted approach that took advantage of available police recorded residential burglary data was used to (1) increase the speed and severity of punishment for identified serially offending burglars, (2) increase the associated risk of offending by identifying (and registering) undocumented individuals (also referred to as a "floating" population) living in Beijing known to commit offences at higher rates [32], and (3) to target residential burglary events through a coordinated hotspot policing approach. The analysis of the police recorded crime data for residential burglary ultimately led to a large number of serial offending burglary arrests and prosecutions. The second component of the approach adopted during the "Strike Hard" campaign on residential burglary during this period effectively identified individuals that belonged to the unregistered transient communities that exist within Beijing. Police inspected those locations identified as possibly housing this unregistered floating population each month during "Strike Hard" and 
registered all individuals they came across from this group thus increasing the associated risk of committing an offence during the campaign. Lastly, those places and times that residential burglary was known to concentrate received a higher volume of street patrol by uniformed police in vehicles and on foot, as well as plain clothes officers.

There are two components of "Strike Hard" that are measurable. The first relates to the perception, if any, of improved guardianship as a direct result of the increased presence by police on the street during the campaign. The second and more quantitative component relates to the measurable differences (if any) associated level of burglary along with the spatiotemporal clustering of burglary events in Beijing during this period. In the section that follows, we outline the analytic plan, data, and methods employed to address this second measurable component of "Strike Hard" to analyze its effectiveness for reducing and possibly sustaining a reduction in the spatiotemporal clustering of burglary incidents, as well as extending techniques that are currently utilized for measuring this concentration of events.

To achieve this and to also test the generalizability of spatiotemporal burglary concentration findings, we propose three specific hypotheses:

Hypothesis (H1). Patterns of repeat and near repeats burglary incidents are evident in Chaoyang district in Beijing across the (a) pre-"Strike Hard", (b) "Strike Hard", and (c) post-"Strike Hard" periods.

Hypothesis (H2). Where repeat and near repeat burglary incidents occur during the pre-"Strike Hard" period there will be less clustering of these crime events during the "Strike Hard" period.

Hypothesis (H3). Where repeat and near repeats occur during the "Strike Hard" period there will be more clustering of these crime events during the post-"Strike Hard" period as the increased guardianship mechanism provided through the hotspot policing component of the intervention will have been removed.

In the section that follows, we discuss data collection, how data were cleaned and processed, as well as the methods that are utilized herein. A series of descriptive and inferential techniques were used to measure the nature and extent of the burglary patterns across three specific temporal windows: pre-"Strike Hard", "Strike Hard", and post-"Strike Hard". Next, the repeat and near repeat analysis of pattern of residential burglary events in Chaoyang district in Beijing, China is conducted for these same periods. Finally, a second novel approach that extends the current repeat and near repeat technique to compare sets of repeat and near repeat patterns across different temporal periods was applied to better understand changes, if any, in the spatiotemporal clustering of residential burglary events. Similarities and differences in the associated patterns are considered along with a discussion about the implication of these findings for future repeat and near repeat studies and "Strike Hard" as a response for residential burglary prevention in the Chinese context are considered.

\section{Materials and Methods}

In this study, the impact of "Strike Hard" on the variation of repeat and near repeat residential burglary events in the Chaoyang district in Beijing, China is examined (see Figure 1). Chaoyang is one of six core districts in Beijing, that constitute the core inner urban area of the city and is surrounded by a further 10 additional remote administrative districts. In 2011, 18.2\% of Beijing's population resided in Choayang and 19.8\% of reported crimes in Beijing (reported in Beijing's 2011 Statistical Yearbook) occurred there. Police recorded crime data were collected before, during and after the "Strike Hard" campaign in Chaoyang and the associated repeat and near repeat pattern was analyzed for each respective period. The crime dataset covered a period of 31 months beginning in June 2009 and continued through until the end of December 2011. The data were accessed via the Crime Recording Database (CRD) from the Beijing Municipal Public Security Bureau (BMPSB). The crime data were divided into three different temporal period categories: pre-"Strike Hard", "Strike Hard", and post-"Strike Hard". More specifically, residential burglary events that took place between 13 June 2009 and 12 June 2010 were designated to the pre-"Strike Hard" period, 13 June 2010 to 31 December 
2010 was placed into the "Strike Hard" period, and 1 January 2011 to 31 December 2011 represented the post-"Strike Hard" period. There is no precise date for the cessation of "Strike Hard" in 2010, but according to the official report the special campaign persisted until the end of the year, consequently the final six months of 2010 represent the treatment period. The original dataset included a total of 13,266 residential burglary events that took place across all three periods. After geocoding and cleaning the data, a total of 12,286 properly geocoded and validated residential burglary events remained. The geocoding accuracy $(92.6 \%)$ was larger than the $85 \%$ minimum hit rate threshold established to confidently analyze spatial point patterns [33]. The final dataset utilized in the analysis that follows included both the latitude/longitude and date/time for the remaining 12,286 geocoded residential burglary events.

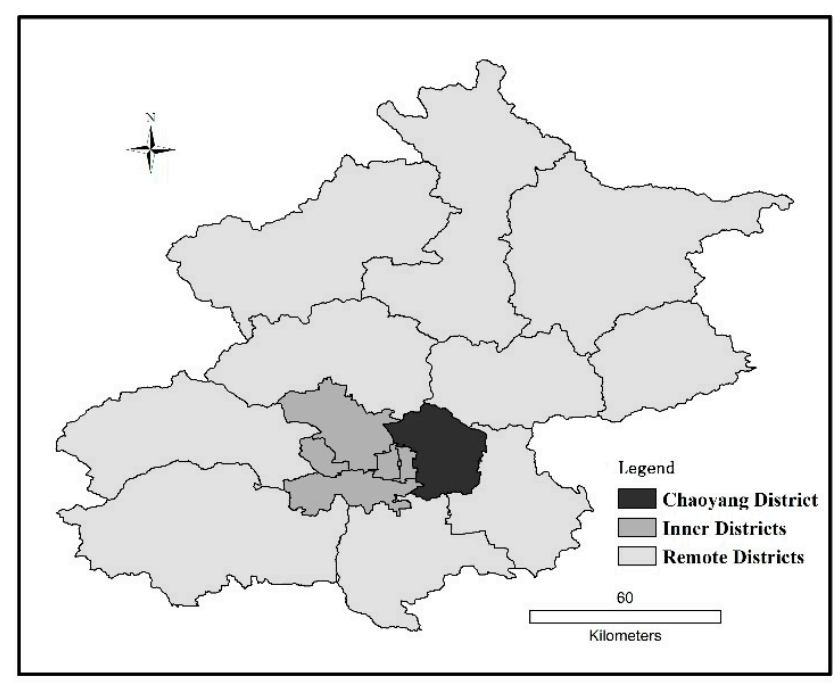

Figure 1. Beijing boundary profile and location of Chaoyang.

To begin with, some exploratory, descriptive, and inferential techniques were used to get a sense of the general trends associated with the three temporal periods of interest. First, a time-series of the daily burglary counts across the entire period along with a line of best fit for each respective temporal period provides some evidence for the differences associated with each category. To supplement this, some descriptive statistics associated with the daily counts were calculated and an ANOVA was used to determine if, on average, residential burglary for the pre-"Strike Hard", "Strike Hard", and post-"Strike Hard" periods were significantly different from one another.

In what follows, an analytical technique pioneered by Knox [34], utilized by epidemiologists to quantify the spatiotemporal clustering of infections [35], and later introduced by for the analysis of repeat and near repeat burglary events was utilized for all three temporal window categories [13]. The Knox test provides a measure of how events cluster across both space and time, rather than focusing on a singular dimension of either space or time. The method compares every event in a dataset with all other events in a dataset recording both the spatial and temporal distances between them. The observed cell counts are organized in an array by both distance and temporal bandwidths. A Monte Carlo simulation is then used to generate a random sample from all possible permutations of the times and locations across all events that is then compared to the observed spatiotemporal event-pairs in the original array. This enables the null hypothesis that the observed cell counts (for the shortest space-time chains) could have occurred on a chance basis to be tested. The null hypothesis of spatiotemporal randomness can then be subsequently rejected if a large percentage (say $95 \%$ or $99 \%$ ) of the events in the original array occurred closer in space and time than in the random permutations generated from the Monte Carlo simulation [3]. Further, a Knox Ratio (KR) is also determined for each respective cell in the original matrix by calculating the ratio of observed spatiotemporal event-pairs 
with the mean of those event-pairs generated from the Monte Carlo simulation. The formalized algorithm that underpins the near repeat analysis herein is available in Appendix A.

Spatial bandwidths were guided by both previous near repeat studies $[5,6,12,18]$ as well as the underlying geography of the Chaoyang district in Beijing. More specifically, five 1000-m distance bandwidths were selected as $1000 \mathrm{~m}$ represents the approximate average distance of a single block in the Chaoyang district. It is important to note that this particular spatial bandwidth is larger than what has been used in many previous repeat/near repeat studies on the communicability of burglary risk, but was also in line with these same studies in terms of using average block distance. Various sensitivity tests including ANN and Ripley's K function were also used to help identify an appropriate spatial bandwidth for the repeat and near repeat analysis with results suggesting a $1000 \mathrm{~m}$ bandwidth to test potential within block spillover was most appropriate [36,37]. Given the physical layout of the Chaoyang district, the distance between events was calculated using Manhattan distance, as opposed to Euclidean distance or "as the crow flies". Conversely, Manhattan distance is calculated by summing the difference between the $X$ coordinates of two points to the difference between the $Y$ coordinates and thus better approximates how people travel both vertically and horizontally across more urban landscapes [38].

The near-repeat analysis was conducted two times with varying temporal bandwidths of 1- and 7-days for the pre-"Strike Hard", "Strike Hard" and post-"Strike Hard" periods. The selection of these temporal bandwidths was similar to the spatial bandwidth selection in that it was guided by a combination of previous near repeat studies that used multiple bandwidths $[5,24,39,40]$. Utilizing various temporal bandwidths enables us to better determine when the near repeat pattern is most pronounced. More specifically, if significant clustering occurred during a 1-day window as opposed to the 7-day window than the former is more optimal.

A statistical significance level of $p<0.001$ was selected and 999 Monte Carlo simulations for the pre-"Strike Hard", "Strike Hard", and post-"Strike Hard" periods along with the two different temporal bandwidths generated KRs for each spatiotemporal combination. Those KRs that are both greater than 1.20 (interpreted like an Odds Ratio, meaning a minimum of $20 \%$ more repeat or near repeats occurring than expected on a chance basis) and with a significance level of $p<0.05$ considered a spatiotemporal cluster [39].

In addition to the repeat and near-repeat analysis that seeks to find space-time clustering, an independent-samples randomization test was used to identify significant differences, if any, that exist between spatiotemporal clusters for the three discrete periods: (1) the pre-"Strike Hard to "Strike Hard" periods and the (2) the "Strike Hard" to post-"Strike Hard" period. The approach allows us to answer the more specific question regarding how the spatiotemporal clustering of burglary events in this particular district in Beijing changed during the "Strike Hard" period, and also to determine if there was a change, if it was sustained in a significant way after the cessation of the intervention.

The latter approach is simple, assume $N_{1}$ (pre-"Strike Hard) and $N_{2}$ ("Strike Hard") are two distinct arrays that include the original spatiotemporal event data, the KRs for each respective array are generated and the difference between the originally observed $K R s$ is computed and stored in an array. Next, a new array is generated that contains all the data from the two original arrays (the length of the new array is $N=N_{1}+N_{2}$ ) and the temporal component of each spatiotemporal pair is randomly shuffled and subsequently redistributed into the original arrays; from these new arrays, new repeat and near-repeat KRs are calculated and their differences are computed and compared with the original observed difference between KRs. This process is then repeated (in this instance, 999 times) using Monte Carlo simulation, thus generating a distribution of potential KR differences. The distribution of simulated KR differences is then used to determine significance. This is done by calculating the number of times the simulated differences are as large or larger than the originally observed differences between KRs. A more formal explanation of this new technique for comparing sets of KRs for differences can be found in Appendix B. 


\section{Results}

\subsection{Descriptive Statistics}

A time series of the daily frequency of residential burglary for the study period beginning in June 2009 and concluding in December 2011 can be visualized in Figure 2 below. Moving from the far left of Figure 2 to the right, there are three respective panels. The black line in the first panel represents the 4,154 residential burglary events that took place in the Chaoyang district of Beijing across the pre-"Strike Hard" period, the black line in the middle panel represents the 2,245 residential burglary events that occurred across the same area during "Strike Hard" period, and the black line in the panel on the far right of Figure 2 represents the 5,887 residential burglary events that occurred in the post-"Strike Hard" period. The associated lines of best fit, in red, is also provided for the different stages. It is clear when visualizing the associated pattern that there are three rather distinct trends associated with each respective period with what appears to be a greater degree of variance in the daily patterns associated with the period before and after the "Strike Hard" campaign. The trend line during the pre-"Strike Hard" period presents a potential challenge in interpreting findings as it is suggestive of a decreasing number of burglary events, while the reverse is true during the post- "Strike Hard" period where there is an upward trend.

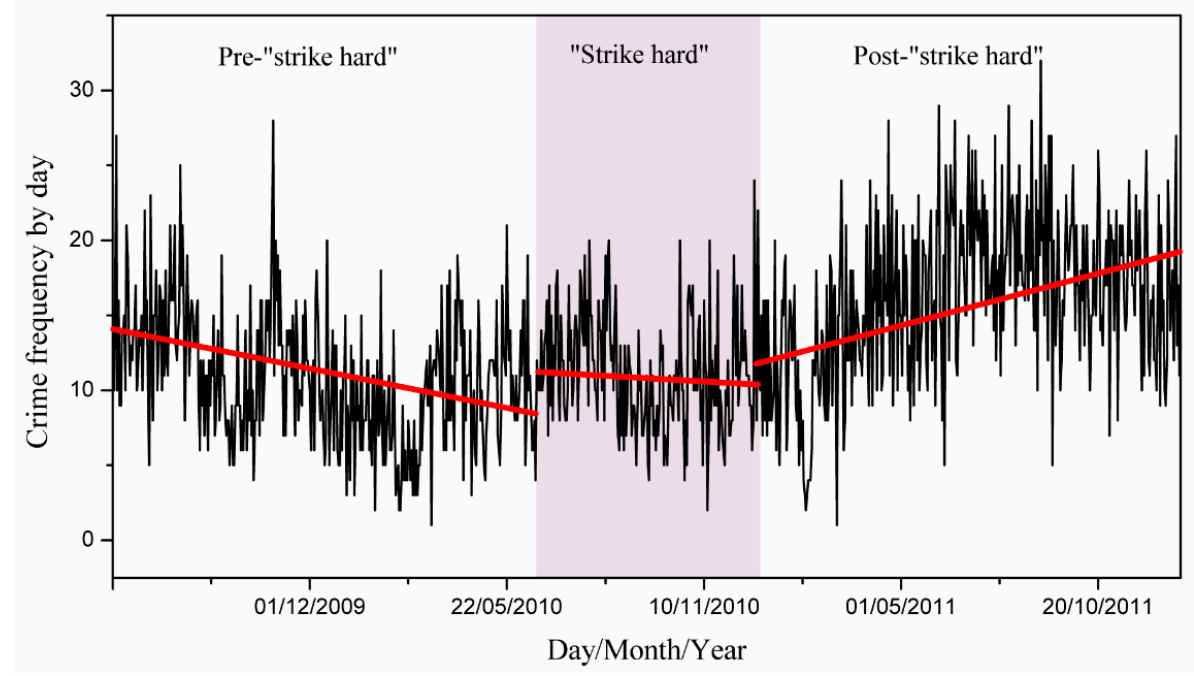

Figure 2. Time series of residential burglary in Chaoyang district, Beijing before (June 2009 through June 2010), during (June through December 2010) and after (January through December 2011) "strike hard" days.

Some basic descriptive statistics for the three temporal periods are provided in Table 1. The daily frequency of residential burglary events for the pre-"Strike Hard" and the "Strike Hard" period are remarkably similar at 10.93 and 11.11, respectively. However, there was greater variance during the pre-"Strike Hard" period. The mean residential burglary count for the period immediately following the end of the campaign was considerably larger than the previous two periods, with approximately 5 additional burglaries per day.

Table 1. Descriptive statistics to the crime occurred pre-, during, and post-Strike Hard days.

\begin{tabular}{cccccc}
\hline Period & Total Days & Mean & Std. Dev. & Min & Max \\
\hline Pre-Strike Hard & 365 & 10.93 & 4.48 & 1 & 28 \\
Strike Hard & 202 & 11.11 & 3.93 & 2 & 24 \\
Post-Strike Hard & 365 & 16.13 & 5.51 & 1 & 32 \\
\hline
\end{tabular}


Visualizing and describing the data provide some indication of potential differences that may exist across these periods, but an ANOVA was used to more directly test for differences in group means. The results suggest that there is no significant difference between the mean level of burglary events in pre-"Strike Hard" and "Strike Hard" stage ( $p=0.911)$, while post-"Strike Hard" is significantly different from the pre-"Strike Hard" and "Strike Hard" periods (both at $p<0.001$ level). The summary test results suggest that there was a significant rebound in burglary events when "Strike Hard" concluded.

\subsection{Repeat and Near-Repeat Pattern Analysis}

Following the descriptive analysis, repeat and near-repeat patterns of residential burglary for the different temporal window periods are analyzed using Knox Ratios and Monte Carlo simulation. The $X$-axes that run along the bottom of Figure 3 below represent the various spatial bandwidths starting with the initiator burglary incident, the 0-1000 m area from that incident, the 1000-2000 m area, $2000-3000 \mathrm{~m}, 3000-4000 \mathrm{~m}$, and lastly, the $4000-5000 \mathrm{~m}$. The $Y$-axes reflect the two bandwidths of 1-day that takes stock of individual days from the initiator event through to those repeats and near repeats that occur beyond 5 days, and also the 7-day bandwidth that captures those repeats and near repeats for the first week of the initiator burglary event and each successive week and beyond 5 weeks. The two panels to the far left in Figure 3 display the KRs for residential burglary for the pre-"Strike Hard" period, the middle two panels are the "Strike Hard" period, and those two figures on the far right are for the post-"Strike Hard" period. The cells in Figure 3 that are colored are indicative of a statistically significant repeat or near-repeat pattern with each respective cell containing the space-time associated Knox Ratio.

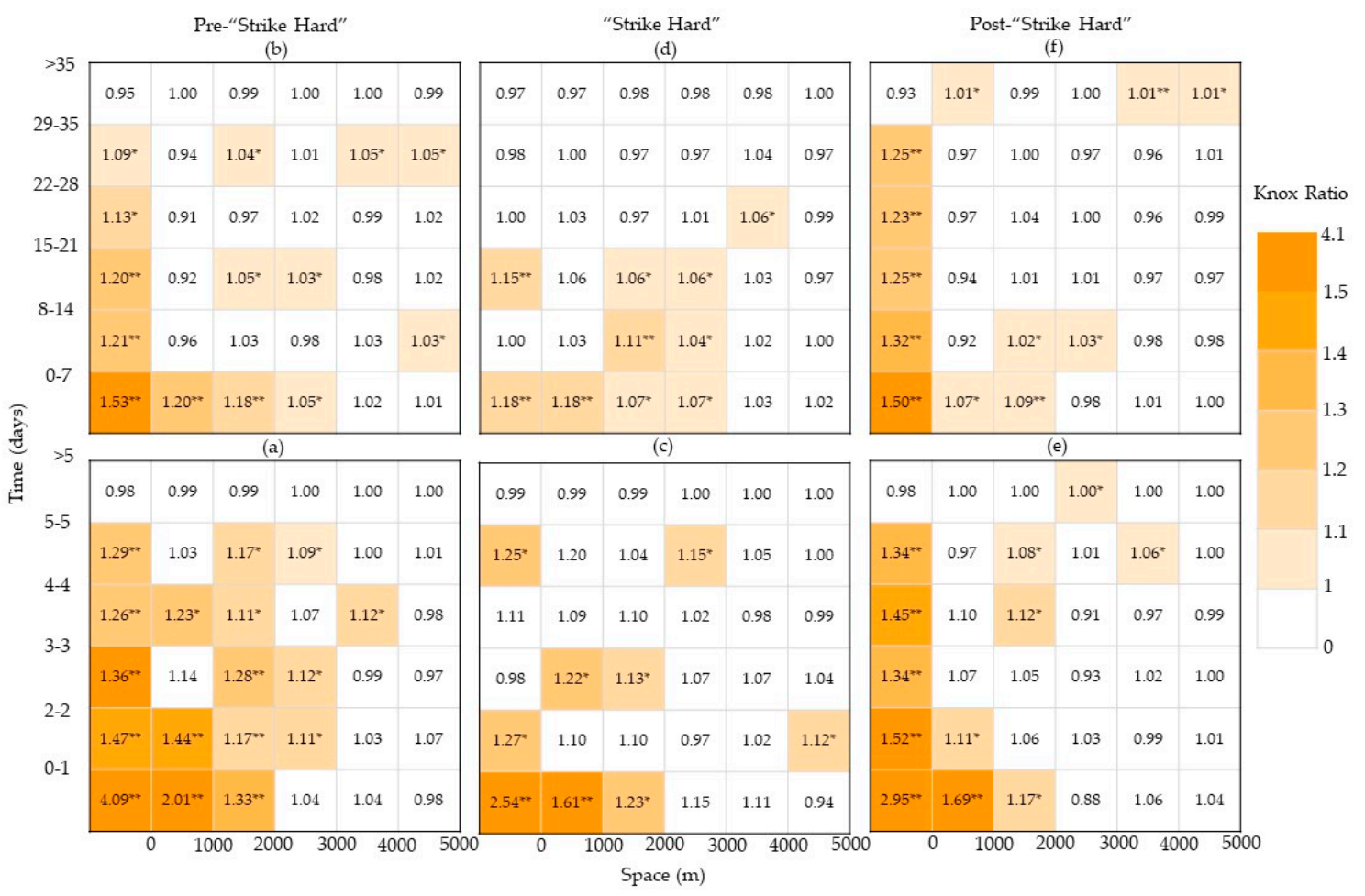

Figure 3. Knox ratios (KRs) for the pre-"Strike Hard" (a,b), "Strike Hard" (c,d), and post-"Strike Hard" $(\mathbf{e}, \mathbf{f})$ periods at different spatiotemporal bandwidths (shading indicates those KRs that are significant). ${ }^{*} p<0.05 ;{ }^{* *} p<0.01 ; * * *<0.001$.

Starting with the smallest temporal bandwidth of a 1-day in the lower left hand corner of Figure 3a, extreme repeat victimization is observed at same location within 0-1 day with the probability of repeat offending following an initiator reaching as high as 309\%, $47 \%$ after 2 days, and $36 \%$ at 3 days, $26 \%$ at 4 days, and $29 \%$ at 5 days. Although less pronounced, near-repeat occur within $1000 \mathrm{~m}$ of the initiator 
event at the 1 -day window by $101 \%, 2$ days by $44 \%$, and 4 days by $23 \%$. A very similar near-repeat pattern emerges for the 1000-2000 $\mathrm{m}$ bandwidth with significant spatiotemporal clustering persisting at the 1-day interval for up to 5 days. There is also some evidence that near-repeat spatiotemporal clustering remains elevated across the 2000-3000 m bandwidth at the 1-day interval at 2, 3, and 5 days after the initiator burglary, as well as for the $3000-4000 \mathrm{~m}$ at 4 days after. A similar repeat and near-repeat pattern emerges from the 7-day window bandwidth (b) with an elevated risk during the initial week after an initiator burglary incident; however, this pattern only persists in a consistent way for the repeat pattern across 5 weeks.

Results for the "Strike Hard" campaign, the two middle panels in Figure 3c,d, starting with the smallest temporal bandwidth in the lower left hand (c) suggest repeat victimization is observed at same location within 0-1 day with the probability of repeat victimization following an initiator reaching at $154 \%, 52 \%$ after 2 days, $34 \%$ at 3 days, $45 \%$ at 4 days, and $34 \%$ at 5 days. Near-repeats within $1000 \mathrm{~m}$ of the initiator event at the 1-day window were $69 \%$ and $11 \%$ for 2 days after the initiator, while between 1000 and 2000 m near-repeats were $17 \%, 12 \%$, and $8 \%$ greater than what would be expected on a chance basis for the first, fourth, and fifth days after the initiator event respectively. The only other significant repeat patterns that emerged during the "Strike Hard" period between 2000-3000 m at 5-days where an increase of $15 \%$ was expected, but also a $12 \%$ increase in associated risk between $4000-5000 \mathrm{~m}$ the day after an initiator burglary event. A less pronounced repeat and near-repeat pattern emerged for the 7-day window (d) where significant increases of between $7 \%-18 \%$ occurred primarily during the initial week after an initiator event.

Finally, the two panels on the right side of Figure 3e,f for the post-“Strike Hard" period starting with the smallest temporal bandwidth of a single day suggest repeat victimization is observed at same location within 0-1 day with the probability of repeat victimization following an initiator reaching at $195 \%, 27 \%$ after 2 days, and $25 \%$ at 5 days. Near repeats within $1000 \mathrm{~m}$ of the initiator event at the 1-day window were $61 \%$ and $22 \%$ for 3 days after the initiator, while between 1000 and $2000 \mathrm{~m}$ near repeats were $23 \%$ and $13 \%$ greater than what would be expected on a chance basis for the first and third days after the initiator event respectively. The only other significant repeat patterns that emerged during the post-"Strike Hard" period occurred between 3000-4000 m at 5-days where an increase of $6 \%$ was expected. The repeat pattern for the 7-day window (f) was significant from the first week with an increased risk of $50 \%$ through the fifth week with an increase of $25 \%$, while the near repeat burglary risk increased by $7 \%$ and $9 \%$ during this first week for the $0-1000 \mathrm{~m}$ and $1000-2000 \mathrm{~m}$ bandwidths, respectively.

\subsection{KR Difference Test}

The repeat and near repeat analysis demonstrates that residential burglary has different spatiotemporal patterns across the pre-"Strike Hard", "Strike Hard", and post-“Strike Hard" periods. Furthermore, it is evident that there is a variation of repeat or near repeat burglary throughout different stages, which indicates that repeat and near repeat offending appears to have been affected by the enhanced law-enforcement campaign in some way. However, to more formally test that the spatiotemporal risk variation across the three periods was significantly different, further analysis was conducted.

Figure 4 shows the result of a KR difference test between pre-"Strike Hard" and "Strike-Hard period in the left column (a-b) and the "Strike Hard" to post-"Strike-Hard" periods on the right (c-d). Like with the previous figure, the $X$-axes represent the spatial bandwidths while the $Y$-axes represent the temporal bandwidths; however, the coloring associated with each respective cell in Figure 4 is meant to provide direction regarding the intensity of the association spatiotemporal clusters and in itself is not indicative of significance. Put differently, the deeper the orange the larger the increase in degree of repeat and near repeats, the deeper the blue the larger the decrease in the degree of repeat and near repeats. 


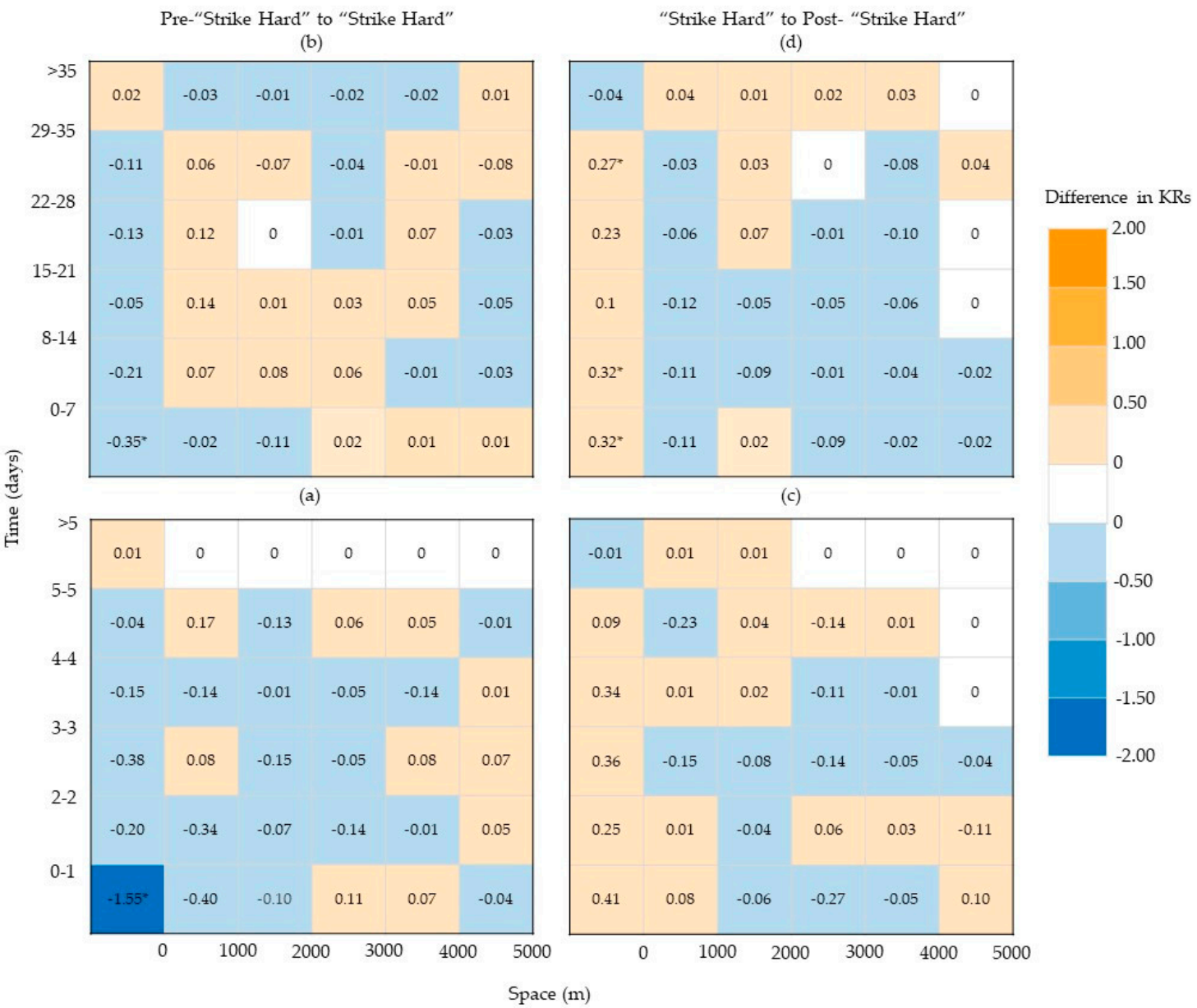

Figure 4. Knox Ratios differences for the pre-"Strike Hard" to "Strike Hard" periods (a,b) and the "Strike Hard" to post-“Strike Hard" periods (c,d) at different spatiotemporal bandwidths. * $p<0.05$; ** $p<0.01 ;{ }^{* * *} p<0.001$

The two left panels in Figure 4a,b display the KR differences for repeat and near-repeat residential burglary for the pre-"Strike Hard" to "Strike Hard" period. The abundance of blue colored grid cells is indicative of a cooling effect on the repeat and near repeat pattern of residential burglary events that took place during the "Strike Hard" campaign. Of note, only repeat burglary events on the day and for the week following a burglary event were significantly different with a decrease of one day repeats of $155 \%$ and of $35 \%$ in repeats across the initial week.

The two panels on the right of Figure $4 \mathrm{c}$, $\mathrm{d}$ display the KR differences for repeat and near repeat residential burglary for the "Strike Hard" to post-"Strike Hard" period. While there were no significant results for the single day bandwidth (c), there is a greater number of orange colored grid cells, thus indicating that the cessation of the "Strike Hard" period ultimately led to an increase in the associated repeat and near-repeat residential burglary risk, although the pattern suggests that this was strongest for repeat burglary events. Like with the single day bandwidth results, those for the 7-day window (d), suggest an increased risk of repeat burglary events with the first week, second week, and fifth week experiencing a significant difference. While there were no other significant differences for the 7-day window for all repeat spatiotemporal bandwidths, there some evidence to suggest a potential reduction in risk occurring with a large number of cooler blue coloring for these cells.

\section{Discussion}

A number of descriptive and inferential analyses were undertaken to both explore and better understand the influence of "Strike Hard" on the associated burglary patterns in Chayong district in 
Beijing. Some interesting and paradoxical findings emerged in relation to the analyses that require careful consideration. To begin, the simple, but illustrative downward trend line during the pre-"Strike Hard" period is suggestive of what is commonly referred to in the situational crime prevention literature as anticipatory benefits [41]. More precisely, anticipatory benefits are the premature crime prevention effects that occur prior to the implementation of the actual intervention. It is plausible to extrapolate from the results that potentially motivated offenders may have learned of a pending "Strike Hard" campaign and consequently began to modify their behavior accordingly, leading to this decreasing trend going into the actual intervention period. That there was no significant difference with the average number of burglary events between the pre-"Strike Hard" and "Strike Hard" period is interesting and provides some support against this type of intervention for reducing residential burglary events. The final upward trending line and the results from the ANOVA that indicate a significant increase in the post-"Strike Hard" period when compared to the pre- and "Strike Hard" periods both provide evidence against any potential utility for residential burglary prevention from this particular intervention. The additional analyses that more directly tested the various hypotheses are discussed in the next section.

\subsection{Hypothesis 1}

Results from the repeat and near repeat analyses in Chaoyang district in Beijing across the (a) pre-"Strike Hard", (b) "Strike Hard", and (c) post-“Strike Hard" periods provide support to H1. More specifically, the analysis for repeat and near repeat burglary for these set of hypotheses were in line with expectations in that patterns of repeat and near repeat victimization were found to be statistically significant, with patterns reflecting the increased level of risk during the period shortly after an initial burglary event being greater than what would be expected on a chance basis, in addition to areas that were proximal to initiator burglary events.

This evidence lends further support to the nearly ubiquitous finding regarding the non-random nature of burglary events across time and space, the elevated risk associated with both repeat and near-repeat burglary particularly during the period immediately after initiator events, and the realistic possibility of successfully reducing future burglary events given the predictable nature of this clustering. Importantly, findings are also in line with several recent non-Western repeat/near-repeat burglary studies that have been conducted in that the patterns that emerge [42-44].

\subsection{Hypothesis 2}

The second hypothesis $(\mathrm{H} 2)$ sought to measure the nature and extent of differences, if any, in the degree of repeat and near repeat burglary clusters that emerged in relation to the pre-"Strike Hard" and "Strike Hard" periods. It was believed that the combination of crime preventing mechanisms, namely the increased swiftness and severity of punishment associated with being arrested for a burglary coupled with the increased presence of capable guardianship stemming from the hotspot policing approach would drive down repeat and near repeat burglary events. More specifically, the expected nature of the effect associated with the comparison between the pre-"Strike Hard" and "Strike Hard" period was less clustering of repeat and near repeat burglary events as a result of the "Strike Hard" campaign. This was the case in relation to the repeat effect with a significant difference found for repeats up to two weeks after an initiator burglary event took place. Results for the near repeat clustering, particularly across the first 5-day period, were not as clear and while they did suggest a downward trend in spatiotemporal clustering of burglary events, although not significantly so.

These results provide some evidence for the effectiveness of the "Strike Hard" campaign at reducing the spatiotemporal clustering of burglary events, but also appear paradoxical as they relate to the earlier descriptive and inferential analyses that suggested there was no significant difference in the associated burglary counts across these two periods. However, further consideration for what might be driving a reduction of risk for repeats and for some near repeats, but also not driving down the average count during these distinct periods may be an indication of spatial displacement [45]. 
More specifically, if burglars offend at a particular target home and the hotspot policing component of the "Strike Hard" intervention increases the associated risk by strategically positioning patrols in this area it is possible that offenders may simply move to other areas around the Chaoyang district where the perceived risk is lower. Given the total size of the district and the contrast in results this seems the most logical explanation for the underlying patterns that emerged from these two separate analyses.

\subsection{Hypothesis 3}

The final hypothesis suggested that a direct consequence of the cessation of the "Strike Hard" period would be a bounce back in relation to the degree of repeat and near repeat burglary clusters. More specifically, when the increased guardianship mechanism provided through the hotspot policing component of the intervention is removed there will be an increased risk for repeat and near repeat burglary events and for this particular set of comparisons the findings indicate that this did occur. In other words, the degree of spatiotemporal clustering in the post-"Strike Hard" period was in most instances larger than the "Strike Hard" period, and in some cases significantly so.

This finding is in line with the descriptive and inferential findings that were undertaken at the start of the analysis that showed not only an upward trending regression line for the post-"Strike Hard" period, but a statistically significant increase in the average count of burglaries that took place during this period as well. These findings comport well with one another, and also provide some evidence regarding the role of capable guardianship in relation to "Strike Hard" in that upon the intervention ending there was a statistically significant increase in the associated risk for repeat and near repeat burglary victimization.

\subsection{What Drove the Changes}

The multi-faceted approach to the reduction of residential burglary in Beijing described in an earlier section of this paper suggested that "Strike Hard" revolved around (1) increasing the speed and severity of punishment of identified serial offending burglars, (2) the identification and registering of undocumented individuals living in Beijing, and (3) a coordinated hotspot policing approach. While difficult to tease apart the contribution, or lack thereof, for each respective component of "Strike Hard" there are a number of possible explanations for what the results herein suggest.

More specifically, the influence of increasing the speed and severity of punishment of identified serial offending burglars, at least in part, is predicated upon (a) identifying known offenders, whether that be through existing legal cases where individuals are awaiting trial, (b) matching undocumented individuals to burglary incidents, and/or (c) identifying new burglars through coordinated hotspot policing. Each of the abovementioned mechanisms may individually or combinatorically contribute to a reduction in the degree of repeat and near repeat burglary events during the "Strike Hard" period.

The findings are suggestive of a large number of serial offending burglary arrests and prosecutions, but what is less clear is the proportion of arrests during the "Strike Hard" campaign that stemmed from the identification and incapacitation of individuals who belonged to the unregistered "floating" communities that exist within Beijing. Previous research on this particular demographic group in China has suggested that they are responsible for a disproportionate amount of crime, and for property crime in particular [32]. The extent to which this particular component of the "Strike Hard" campaign influenced both the degree of change in spatiotemporal burglary clusters both during and post-"Strike Hard" needs to be better understood.

The final component of "Strike Hard" was a hotspot policing approach that sent uniformed officers on foot and vehicles to those places and times that residential burglary was known to concentrate, along with plain clothes officers. Additional details regarding how this particular component of the campaign was conducted is critical to developing a comprehensive understanding of the potential impact of "Strike Hard". One can extrapolate from the results that there was likely some influence associated with having a greater presence of uniformed and plain clothes officers during the "Strike Hard" period in part because while "Strike Hard" was underway there were statistically significant 
reductions associated with the risk of repeat and near repeat burglary events, but there was some degree of bounce back in relation to repeat and near-repeat burglary clustering that occurred after the campaign commenced. Numerous burglary prevention programs have been developed in different countries and evaluated for their effect, if any, on reducing risk [46-48], however to the authors' knowledge this is the first such study to be conducted in a non-Western setting. Still other studies on street crimes that have used hotspot policing approaches have found a similar displacement decay, whereby after the foot patrols ended the localized effect associated with police as capable guardians during the three months after the experiment ended and a similar crime concentration returned [49].

One caveat—and potential limitation of this study—relates to the difference in spatial bandwidths utilized herein. The majority of Western studies [3,6], and even non-Western studies [21,22], that have sought to examine the spatiotemporal clustering of burglary events have used smaller near-repeat spatial bandwidths. More specifically, the $1000 \mathrm{~m}$ bandwidth used in this study was selected to reflect the average block in the Chaoyang district of Beijing and is approximately 10 times larger than the spatial bandwidths used to measure near repeat burglary patterns in other studies [3]. It is possible that using this larger bandwidth "washed out" some of the potential near repeats that occur within smaller areas within the block in which the initiator event occurred. However, and because of previous research on repeat and near repeat burglary in Beijing that used smaller $100 \mathrm{~m}$ bandwidths in the Chaoyang District found almost no significant near-repeat burglary events within the $1000 \mathrm{~m}$ block, we are not concerned [22].

\section{Conclusion}

In this study, we have examined the repeat and near-repeat residential burglary patterns for the Chayong District in Beijing, China across three distinct periods. The initial approach to testing residential burglary patterns is routinely used for measuring the relative strength of space-time distances that emerge in the extant literature and the associated patterns that emerged were similar to those that have been studies in both Western and non-Western settings for burglary. More specifically, the findings suggested that regardless of the period examined there was a significantly greater degree of repeat and near repeat victimizations in the period immediately following an initiator burglary event than what would be expected on a chance basis.

The paper makes a further, and important contribution, in providing a new technique that enables a statistical comparison between emerging spatiotemporal clusters. More specifically, the approach allows for more direct hypothesis testing for repeat and near repeat patterns across different temporal periods (e.g., pre-"Strike Hard" to Strike Hard) and consequently an improved approach for evaluating the significance, if any, of the communicability of events that emerge across periods of interest. While, the findings suggest that the "Strike Hard" campaign helped reduce repeat burglary risk during the intervention, results from associated count data across the distribution of the three periods of interest does not suggest the intervention reduced burglary in a significant way. Rather, taken together the findings suggest a "backfire" effect with a significantly greater number of burglary events during the post-"Strike Hard" period.

Future studies should seek to tease apart the mechanism, or combination of mechanisms, through which this reduction in the degree of repeat burglary clustering occurred. One approach might include an examination of the number of burglary-related arrests and the associated terms of sentencing during the three respective periods. Such an analysis would help to better quantify the number of serial burglars that were incapacitated during each respective period, and when they were released to better understand whether these offenders drove the initial displacement during the "Strike Hard" period as well as the displacement that appeared to decay in the period after "Strike Hard" ended. Along this same vein another approach should involve the interviewing of offenders, not only in relation to the influence (if any) of the impact of the different components of "Strike Hard", but on the extent to which they had burgled other residences prior to their arrest and sentencing. To date, there has been no research in China - that the authors are aware of — that involves interviewing offenders regarding 
foraging behavior and the influence that either enhanced sentencing or hotspot policing had on their decision to commit a burglary across these distinct periods. These future research avenues will help tease apart the respective contribution, or particular combination of mechanisms, that drive and sustain a decrease in the overall risk of repeat and near repeat burglary events, but also appear to increase the underlying count of burglary incidents.

Author Contributions: Peng Chen conceived the original idea for the repeat and near-repeat analysis, collected the data, conducted the formal analyses, created the first figures and tables, and was responsible for writing parts of the original draft. Justin Kurland helped design the paper, developed the idea for the repeat/near-repeat KR comparison test, generated the repeat/near repeat figures and wrote parts of the original draft as well as editing and reviewing the manuscript. All authors have read and agreed to the published version of the manuscript.

Funding: Support for this research was provided from the Basic Scientific Research Project (2018JKF228), and the Beijing Natural Science Foundation (9192022).

Acknowledgments: We would like to thank the Beijing Municipal Public Security Bureau for providing crime data for this study and the National Engineering Lab for Big Data Applications for Public Security Risk Perception and Prevention.

Conflicts of Interest: The authors declare no conflict of interest.

\section{Appendix A}

1) For $N$ burglary events, the temporal distance $\delta t_{i j}$ and spatial distance $\delta l_{i j}$ between $i$ th and $j$ th burglary events are calculated using equations (1) and (2):

$$
\begin{gathered}
\delta t_{i j}=\left|t_{i}-t_{j}\right| \\
\delta l_{i j}=\left|x_{i}-x_{j}\right|+\left|y_{i}-y_{j}\right|
\end{gathered}
$$

where $j=1,2, \ldots, N, j \neq i, t_{i}$ and $t_{j}$ are temporal locations of $i$ th and $j$ th burglary events in a temporal distance sequence, while $x_{i}, y_{i}$ and $x_{j}, y_{j}$ are the spatial locations of $i$ th and $j$ th burglary events in a spatial distance sequence.

2) Let $\Delta T$ and $\Delta L$ to be temporal and spatial bandwidth, then build an empty $m \times m$ matrix $\Phi_{m, m}$ and fill the matrix with number of event pairs whose temporal and spatial distance locates into the $k$ th temporal and spatial distance zone, for example if

$$
(k-1) \times \Delta T<\delta t_{i j}<k \times \Delta T
$$

and

$$
(k-1) \times \Delta L<\delta l_{i j}<k \times \Delta L
$$

then $\Phi_{k, k}$ would add one, where $k=0,1, \ldots m$.

3) Assuming burglary events are independent from each other in space or time, keep their spatial locations unchanged but randomly shuffle their temporal locations (or shuffle spatial locations but keep temporal locations unchanged), then a group of $N$ burglary events with new temporal locations are generated and their corresponding matrix $\Phi_{m, m}^{h}$ is calculated following step 1) and 2), repeat this process for $n_{s}$ times, where $h=1,2, \ldots, n_{s}$

4) Let $\Gamma_{m, m}$ be the near repeat ratio matrix, then $\Gamma_{k, k}$ would be

$$
\Gamma_{k, k}=\frac{\phi_{k, k}}{\sum_{h=1}^{n_{s}} \phi_{k, k}^{h} / n_{s}}
$$

The significance for $\Gamma_{k, k}$ is then calculated as per Equation (6):

$$
p=1-\frac{n_{e}}{n_{s}}
$$

where $n_{e}$ is the number of times that $\Phi_{k, k}$ is larger than $\Phi_{k, k}^{h}$. 


\section{Appendix B}

1) For $N_{1}$ burglary events whose temporal location is $t_{i}$, spatial location is $x_{i}, y_{i}\left(I=1,2, \ldots N_{1}\right)$; for $N_{2}$ burglary events whose temporal location is $t_{j}$, spatial location is $x_{j}, y_{j}\left(j=1,2, \ldots N_{2}\right)$, generate KRs matrix $\Gamma_{m, m}^{o b d i f, 1}$ and $\Gamma_{m, m}^{o b \_d i f, 2}$ following the algorithms in Appendix A, then compute the KRs difference matrix using following equation:

$$
\Gamma_{k, k}^{o b \_d i f}=\Gamma_{k, k}^{o b \_d i f, 1}-\Gamma_{k, k}^{o b \_d i f, 2} \text {, where } k=1,2, \ldots m
$$

2) Build a new empty array to include $N_{1}$ and $N_{2}$ burglary events' temporal locations and spatial locations, the new array length is $N\left(N=N_{1}+N_{2}\right)$, then keep the spatial locations unchanged and randomly shuffle the temporal locations (or keep the temporal locations unchanged and randomly shuffle the spatial locations), redistribute the burglary events temporal locations and spatial locations into new arrays whose lengths are $N_{1}$ and $N_{2}$, respectively.

3) For redistributed temporal locations $t^{q, 1}{ }_{i}$ and spatial locations $x^{q, 1}{ }_{i}, y^{q, 1}{ }_{i}$ in array whose length is $N_{1}\left(i=1,2, \ldots N_{1}\right)$, and for redistributed temporal locations $t^{q, 2}{ }_{j}$ and spatial locations $x^{q, 2}{ }_{j}, y^{q,{ }^{2}}{ }_{j}$ in array whose length is $N_{2}\left(j=1,2, \ldots N_{2}\right)$, generate the KRs matrix $\Gamma_{m, m}^{q, 1}$ and $\Gamma_{m, m}^{q, 2}$ following the algorithms in Appendix A, compute the KRs difference matrix using following equation:

$$
\Gamma_{k, k}^{q}=\Gamma_{k, k}^{q, 1}-\Gamma_{k, k^{\prime}}^{q, 2} \text { where } k=1,2, \ldots, m
$$

4) iterate step 2) and 3) for $n_{s}$ times (for example, $n_{s}=999, q=1,2, \ldots n_{s}$ ), and build an empty $m$ $\times m$ matrix $\Phi_{m, m}$ to record the significance test result. The significant level recording of the cell $\Phi_{k, k}$ would be:

$$
p=1-\frac{n_{e}}{n_{s}}
$$

where $n_{e}$ is the number of times that $\Gamma_{k, k}^{o b \_d i f}$ is larger than $\Gamma_{k, k^{\prime}}^{q}$ where $q=1,2, \ldots n_{s}, k=1,2, \ldots m$.

\section{References}

1. Wells, W.; Wu, L.; Ye, X.Y. Patterns of Near-Repeat Gun Assaults in Houston. J. Res. Crime Delinq. 2012, 49, 186-212. [CrossRef]

2. Wells, W.; Wu, L. Proactive Policing Effects on Repeat and Near-Repeat Shootings in Houston. Police Q. 2011, 14, 298-319. [CrossRef]

3. Johnson, S.D.; Bernasco, W.; Bowers, K.; Elfers, H.; Ratcliffe, J.; Regert, G.; Townsley, T. Space-time patterns of risk: A cross national assessment of residential burglary victimization. J. Quant. Criminol. 2007, 23, 201-219. [CrossRef]

4. Ratcliffe, J.H.; McCullagh, M.J. Identifying repeat victimization with GIS. Br. J. Criminol. 2004, 38, 651-662. [CrossRef]

5. Ratcliffe, J.H.; Rengert, G. Near-repeat patterns in Philadelphia shootings. Secur. J. 2008, 21, 58-76. [CrossRef]

6. Piza, E.L.; Carter, J.G. Predicting Initiator and Near Repeat Events in Spatiotemporal Crime Patterns: An Analysis of Residential Burglary and Motor Vehicle Theft. Justice Q. 2017, 35, 842-870. [CrossRef]

7. Wu, L.; Xu, X.; Ye, X.; Zhu, X. Repeat and near-repeat burglaries and offender involvement in a large Chinese city. Cartogr. Geogr. Inf. Sci. 2015, 42, 178-189. [CrossRef]

8. Cohen, L.E.; Felson, M. Social change and crime rate trends: A routine activity approach. Am. Sociol. Rev. 1979, 44, 588-608. [CrossRef]

9. Hollis, M.E.; Felson, M.; Welsh, B.C. The capable guardian in routine activities theory: A theoretical and conceptual reappraisal. Crime Prev. Community Saf. 2013, 15, 65-79. [CrossRef]

10. Trevaskes, S. Policing Serious Crime in China: From 'Strike Hard' to 'Kill Fewer'; Routledge: New York, NY, USA, 2012.

11. Song, G. On the "Strike-hard Campaign" in the Perspective of Criminal Integration. J. Jiangsu Admin. Inst. 2004, 4, D924. 
12. Grubb, J.A.; Nobles, M.R. A Spatiotemporal Analysis of Arson. J. Res. Crime Delinq. 2016, 53, 66-92. [CrossRef]

13. Townsley, M.; Homel, R.; Chasellng, J. Infectious burglaries a test of the near repeat hypothesis. Br. J. Criminol. 2003, 43, 615-633. [CrossRef]

14. Bernasco, W. Them Again? Same-Offender Involvement in Repeat and Near Repeat Burglaries. Eur. J. Crime 2008, 5, 411-431. [CrossRef]

15. Bowers, K.; Johnson, S.D. Who commits near repeats? A test of the boost explanation. West. Criminol. Rev. 2004, 5, 12-24.

16. Johnson, S.D.; Summers, L.; Pease, K. Offender as forager? A direct test of the boost account of victimization. J. Quant. Criminol. 2009, 25, 181-200. [CrossRef]

17. Sturup, J.; Rostami, A.; Gerell, M.; Sandholm, A. Near-repeat shootings in contemporary Sweden 2011 to 2015. Sec. J. 2017, 31, 73-92. [CrossRef]

18. Haberman, C.P.; Ratcliffe, J.H. The Predictive Policing Challenges of Near Repeat Armed Street Robberies. Polic. A J. Policy Pr. 2012, 6, 151-166. [CrossRef]

19. Marchione, E.; Johnson, S.D. Spatial, temporal and spatio-temporal patterns of maritime piracy. J. Res. Crime Delinq. 2013, 50, 504-524. [CrossRef]

20. Townsley, M.; Johnson, S.D.; Ratcliffe, J.H. Space time dynamics of Insurgent activity in Iraq. Secur. J. 2008, 21, 139-146. [CrossRef]

21. Chen, P.; Yuan, H.Y.; Li, D.S. Space-time analysis of burglary in Beijing. Secur. J. 2013, 26, 1-15. [CrossRef]

22. Chainey, S.P.; Silva, B.F.A. Examining the extent of repeat and near repeat victimisation of domestic burglaries in Belo Horizonte, Brazil. Crime Sci. 2016, 5, 1-10. [CrossRef]

23. Youstin, T.J.; Nobles, M.R.; Ward, J.T.; Cook, C.L. Assessing the generalizability of the near repeat phenomenon. Crim. Justice Behav. 2011, 38, 1042-1063. [CrossRef]

24. Pease, K. Repeat Victimisation: Taking Stock; Crime detection and Prevention Series; Home Office: London, UK, 1998; p. 90.

25. Johnson, S.D. Repeat burglary victimization: A tale of two theories. J. Exp. Criminol. 2008, 4, $215-240$. [CrossRef]

26. Bowers, K.; Johnson, S. Domestic burglary repeats and space-time clusters. Eur. J. Criminol. 2005, 2, 67-92. [CrossRef]

27. Pitcher, A.B.; Johnson, S.D. Exploring Theories of Victimization Using a Mathematical Model of Burglary. J. Res. Crime Delinq. 2011, 48, 83-109. [CrossRef]

28. Short, M.B.; D'Orsogna, M.R.; Brantingham, P.J.; Tita, G.E. Measuring and Modeling Repeat and Near-Repeat Burglary Effects. J. Quant. Criminol. 2009, 25, 325-339. [CrossRef]

29. Johnson, S.D.; Bowers, K. The burglary as clue to the future, the beginnings of prospective hot-spotting. Eur. J. Criminol. 2004, 1, 237-255. [CrossRef]

30. Anderson, D.; Chenery, S.; Pease, K. Biting Back: Tackling Repeat Burglary and Car Crime; Crime Detection and Prevention Series; Home Office: London, UK, 1995; p. 58.

31. Chenery, S.; Holt, J.; Pease, K. Biting Back II: Reducing Repeat Victimization in Huddersfield; Crime Detection and Prevention Series; Home Office: London, UK, 1997; p. 82.

32. Lo, T.W.; Jiang, G. Inequality, crime and the floating population in China. Asian J. Criminol. 2006, 1, $103-118$. [CrossRef]

33. Ratcliffe, J.H. Geocoding crime and a first estimate of a minimum acceptable hit rate. Int. J. Geogr. Inf. Sci. 2004, 18, 61-72. [CrossRef]

34. Knox, G. Epidemiology of childhood leukaemia in Northumberland and Durham. Br. J. Prev. Soc. Med. 1964, 18, 17-24. [CrossRef]

35. Pike, M.C.; Smith, P.G. Disease Clustering: A Generalization of Knox's Approach to the Detection of Space-Time Interactions. Biometrics 1968, 24, 541-554. [CrossRef] [PubMed]

36. Yue,H.; Zhu, X.; Guo, W. An Effective Method to Determine Critical Distances for the Knox Test. In Proceedings of the 2017 25th International Conference on Geoinformatics, Buffalo, NY, USA, 2-4 August 2017; pp. 1-5.

37. Kalantari, M.; Yaghmaei, B.; Ghezelbash, S. Spatio-temporal analysis of crime by developing a method to detect critical distances for the Knox test. Int. J. Geogr. Inf. Sci. 2016, 30, 2302-2320. [CrossRef]

38. Ratcliffe, J.H. Near Repeat Calculator; version 1.3; Temple University: Philadelphia, PA, USA; National Institute of Justice: Washington, DC, USA, 2009. 
39. Braithwaite, A.; Johnson, S.D. Space-time modeling of insurgency and counterinsurgency in Iraq. J. Quant. Criminol. 2012, 28, 31-48. [CrossRef]

40. Grubesic, T.H.; Mack, E.A. Spatio-temporal interaction of urban crime. J. Quant. Criminol. 2008, 24, $285-306$. [CrossRef]

41. Smith, M.J.; Clarke, R.V.; Pease, K. Anticipatory benefits in crime prevention. Crime Prev. Stud. 2002, 13, 71-88.

42. Hino, K.; Amemiya, M. Spatiotemporal analysis of burglary in multifamily housing in Fukuoka City, Japan. Cities 2019, 90, 15-23. [CrossRef]

43. Bediroglu, G.; Bediroglu, S.; Colak, H.E.; Yomralioglu, T. A Crime Prevention System in Spatiotemporal Principles with Repeat, Near-Repeat Analysis and Crime Density Mapping: Case Study Turkey, Trabzon. Crime Delinq. 2018, 64, 1820-1835. [CrossRef]

44. Wang, Z.; Liu, X. Analysis of burglary hot spots and near-repeat victimization in a large Chinese city. ISPRS Int. J. Geo Inf. 2017, 6, 148. [CrossRef]

45. Weisburd, D.; Mazerolle, L. Measuring Immediate Spatial Displacement: Methodological Issues and Problems. In Crime and Place; Eck, J.E., Weisburd, D., Eds.; Criminal Justice Press: Monsey, NY, USA, 1995; pp. 349-359.

46. Stokes, N.; Clare, J. Preventing near-repeat residential burglary through cocooning: Post hoc evaluation of a targeted police-led pilot intervention. Secur. J. 2019, 32, 45-62. [CrossRef]

47. Weems, J. Testing PCSO Cocooning of near Repeat Burglary Locations. Master's Thesis, University of Cambridge, Cambridge, UK, 2014.

48. Fielding, M.; Jones, V. ‘Disrupting the optimal forager': Predictive risk mapping and domestic burglary reduction in Trafford, Greater Manchester. Int. J. Police Sci. Manag. 2012, 14, 30-41. [CrossRef]

49. Sorg, E.T.; Haberman, C.P.; Ratcliffe, J.H.; Groff, E.R. Foot patrol in violent crime hot spots: The longitudinal impact of deterrence and posttreatment effects of displacement. Criminology 2013, 51, 65-101. [CrossRef]

(C) 2020 by the authors. Licensee MDPI, Basel, Switzerland. This article is an open access article distributed under the terms and conditions of the Creative Commons Attribution (CC BY) license (http://creativecommons.org/licenses/by/4.0/). 